\title{
Percutaneous Coronary Intervention for ST Elevation Myocardial Infarction- Unstable-Over 12 Hours From Symptom Onset
}

National Cancer Institute

\section{Source}

National Cancer Institute. Percutaneous Coronary Intervention for ST Elevation

Myocardial Infarction-Unstable-Over 12 Hours From Symptom Onset. NCI Thesaurus.

Code C100002.

A percutaneous coronary intervention is necessary for a myocardial infarction that presents with ST segment elevation and the subject has recurrent or persistent symptoms, symptoms of heart failure or ventricular arrhythmia. The presentation is past twelve hours since onset of symptoms. (ACC) 